\title{
La dimensión ética de la ciencia según Mariano Artigas
}

\section{The Ethical Dimension of Science According to Mariano Artigas}

\author{
RUBÉN HERCE \\ Grupo de Investigación de Ciencia, Razón y Fe (CRYF) \\ Profesor de Filosofía de la Ciencia, Universidad de Navarra \\ rherce@unav.es
}

Resumen. Muchos autores han escrito sobre las relaciones entre ética y ciencia; y lo han hecho desde enfoques muy diversos. En el presente trabajo se analiza cómo lo hizo Mariano Artigas. Este físico, filósofo y sacerdote da gran importancia a la ética a la que considera un supuesto filosófico de la actividad científica. Un análisis detallado de su obra permitirá observar hasta qué punto es importante la ética para dicha actividad. En concreto nos detendremos en: (1) la relación de la ética con el ser humano y con la ciencia; (2) el entrelazamiento y la distinción entre ambas; (3) la importancia de la ética como clave hermenéutica en Popper; y (4) la aparición de la ética antes, durante y después de la actividad científica.

Palabras clave: Ética; Actividad científica; Mariano Artigas; Karl Popper; Supuestos filosóficos de la ciencia.

Abstract. Many authors have written, from different approaches, about the relationships between ethics and science. In this work, we analyze how Mariano Artigas (a physicist, philosopher, and priest) did it. He gives great importance to ethics, which he considers a philosophical presupposition of scientific activity. A detailed analysis of his work allows to understand to what extent ethics is important for science. Specifically, we consider (1) the relationships of ethics with humans and with science; (2) the inter- 
weaving and the distinction between both of them; (3) the importance of ethics as a hermeneutical key in Popper; (4) and the emergence of ethics before, during, and after scientific activity.

Keywords: Ethics; Scientific Activity; Mariano Artigas; Karl Popper; Philosophical Presuppositions of Science.

En la obra de Mariano Artigas, la ética juega un papel esencial. Se remite a ella con frecuencia y en libros como Filosofía de la Ciencia (Artigas 2009) o La Mente del universo (Artigas 2000) se le dedican varios capítulos. Un análisis detallado del concepto de ética en su obra nos permitirá observar cómo se articula una dimensión tan fundamental en su filosofía de la ciencia. En el presente trabajo se han estudiado los textos en los que Mariano Artigas habla de ética. Una primera aproximación permite catalogarlos en tres grupos de los que se hablará en sucesivos apartados: la ética como algo propiamente humano, la relación entre ética y ciencia (a la que se dedicarán varios epígrafes) y la ética como clave hermenéutica en la obra de Karl Popper. Este análisis permitirá a sacar a la luz aspectos implícitos de la obra de Mariano Artigas en los que la ética no es simplemente un complemento, sino motor de la actividad científica.

\section{La ética es humana}

Una de las ideas que más se repite en la obra de Artigas es que la ética es propiamente humana. Así, entre las características únicas de la persona, nuestro autor sitúa la autoconciencia, la auto-reflexión, la capacidad de argumentar y de hablar, la libertad con responsabilidad, la capacidad de encontrar y dar sentido a la vida, la capacidad de amar y comportarse de modo ético, o la capacidad de amar a Dios y de tener un contacto personal con Él (Artigas 2000, 334).

Estas características humanas tienen una base biológica (Artigas 2004, 81) en continuidad con la biología animal, pero irreducible a lo meramente biológico. 
Sin duda, existe una continuidad entre el hombre y los demás animales. Pero, incluso si se admite que el organismo humano proviene de otros organismos a través de la evolución, las características específicamente humanas continúan siendo reales: basta pensar en el conocimiento intelectual, la capacidad de autorreflexión, la capacidad de argumentar, el sentido de la evidencia y de la verdad, la libertad, los valores éticos. (Artigas 1998a, 271)

Plantearse problemas éticos y religiosos, según Artigas, es la principal característica que diferencia a los seres humanos de otros animales, incluidos los primates (Artigas 2004, 81). En otras palabras, “las preguntas que nos hacemos adquieren sentido a la luz de los interrogantes éticos que tratan sobre el sentido de nuestra vida y de nuestras acciones” (Artigas 2009, 134). La actividad humana, por tanto, tendría su más alta manifestación en la conducta ética (Artigas 1998a, 306; 1995, 503) que, sin olvidar su componente social, es propia de cada individuo humano. De hecho, cabría preguntarse qué quedaría de la ética si se difumina su perspectiva en primera persona para dar paso a una mera ética de la tercera persona; o si se atenúan las diferencias entre la ética del hombre y el comportamiento de sus antecesores, o entre el actuar humano y el derivado de la inteligencia artificial.

Para Artigas, las personas son reemplazables si se trata de ejecutar tareas concretas, pero son insustituibles cuando se consideran las dimensiones estrictamente personales -aquellas en primera persona- entre las que se encuentra el obrar ético (Artigas 1995, 448).

Solo un sujeto personal puede entender, reflexionando sobre sus propios conocimientos, planteándose el sentido de lo que conoce y de su propia existencia, y situándose, por tanto, en un plano ético en el cual, con su libertad y responsabilidad individuales, ha de afrontar el problema del bien y del mal. (Artigas 1995, 482)

Aclarado este punto, cabría preguntarse si esta ética propia del ser humano tiene alguna conexión con la ciencia. A primera vista parecería que sí, porque la ciencia es también una actividad propiamente humana en la que los científicos no se limitan simplemente a ejecutar tareas concretas de modo anónimo, sino que comprometen su ser en su actividad científica. Al ser 
humana y en primera persona, la ciencia no puede estar desconectada de la dimensión ética porque no vemos al ser humano dividido en compartimentos estancos. Este común denominador entre ciencia y ética -que ambas son humanas y en primera persona- nos remite a un segundo aspecto de la obra de Artigas: las dimensiones éticas de la ciencia.

\section{Dimensiones éticas de la ciencia}

Si se admite que la búsqueda de la verdad es el objeto central de la tarea científica, no es difícil darse cuenta que esa empresa (1) posee un carácter ético en sí misma y, además, (2) exige un compromiso ético de quienes la llevan a cabo. Son los aspectos objetivo y subjetivo de la ética científica que denominaremos también ética de la ciencia y ética del científico.

Ahora bien, ambos aspectos: ¿se entrelazan o no?; ¿ esa influencia o independencia es buena o no? Para analizarlo nos detendremos brevemente en la dimensión objetiva de la ética científica, que parece las más clara, para después presentar las objeciones a que exista un entrelazamiento entre las dimensiones objetiva y subjetiva de la ciencia. Por último, concluiremos con Artigas en que existe un entrelazamiento fructífero entre ambas dimensiones. Comencemos.

Según Artigas, la ciencia tendría unas bases éticas y conduciría a la difusión de unos valores éticos concretos, no meramente personales (Artigas 2004,172 ). Este elemento ético de la ciencia tendría su propia autonomía respecto a las conductas éticas de los científicos y a sus intereses personales:

La ciencia experimental ya no puede ser considerada como una actividad que se mueve solo por intereses particulares. La búsqueda de la verdad implica desinterés e imparcialidad con respecto a intereses subjetivos; además, corresponde a una de las aspiraciones más importantes del ser humano. En este sentido, se puede decir que la ciencia experimental posee un carácter ético. (Artigas 2009, 105)

El propio progresar de la ciencia concreta unos valores éticos y se los reclama a los científicos. Son valores que se objetivan y se tienden a difundir con 
la ciencia; pero que deben ser aceptados subjetivamente y promovidos por los científicos.

Ahora bien, a la existencia de una ética objetiva de la ciencia se le podrían hacer por lo menos dos críticas. La primera es que: si se entiende la ética como algo radicalmente individual, carente de valores absolutos, en la que todo es relativo a ciertos puntos de vista condicionados por la situación histórica, personal o cultural, entonces lo ideal es que la ciencia esté libre de todo condicionamiento ético, para estar libre de toda influencia subjetiva.

Cierto, diríamos, pero, como hemos visto, no es así como Artigas entiende la ética. Para él la ética no es algo subjetivo y carente de valores absolutos (Artigas 2004,121). Tanto la actividad científica en general como la tarea de cada científico en particular pueden converger hacia esos valores absolutos. Sin ir más lejos, el científico puede y debe buscar una objetividad que la ciencia reclama.

Por otro lado, y esta es la segunda crítica:

En la actualidad, y debido a la complejidad y abstracción de muchas teorías científicas, se discute e incluso se llega a negar la capacidad de la ciencia experimental para alcanzar la verdad. Se ha difundido una mentalidad funcionalista, según la cual se da por inútil o carente de sentido el concepto de verdad objetiva, y se reduce la ciencia a simple instrumento para la técnica; a su vez, a falta de verdades y normas objetivas, la técnica no estaría sometida a ninguna norma ética. (Artigas 2004, 36)

Con este enfoque, ¿a qué tipo de objetividad científica se podría llegar? Si no hay verdad que se pueda alcanzar, parece que se impone una neutralidad ética por lo menos en las dimensiones más técnicas de la ciencia, e incluso en lo que podríamos denominar ciencia pura.

Sin embargo, de modo análogo a como Juan Pablo II (1979, n. 16) subraya la prioridad de la ética sobre la técnica, Artigas también se preguntará:

¿cómo podría sostenerse en la actualidad que la ciencia pura es éticamente neutral, si se tiene en cuenta que, de un modo $u$ otro, cualquier avance científico puede ser utilizado potencialmente con fines económicos o políticos, controlados por los gobiernos y las grandes empresas? (Artigas 2009, 112) 
Hay líneas de investigación que vienen determinadas de antemano por fines económicos o políticos porque la investigación científica exige grandes inversiones que solo están al alcance de los grandes poderes. Ante estas situaciones los científicos tienden a adaptarse, pero no siempre. Hay quienes llegan a abandonar su trabajo cuando ven comprometida su integridad ética o cuando perciben que sus investigaciones podrían emplearse para fines poco éticos. En muchos de esos campos es especialmente importante contar con principios éticos adecuados. Si no, fácilmente se podría admitir que todo lo que resulta técnicamente posible es también lícito.

Si la ciencia y los científicos se desconectan de la búsqueda ética de la verdad que la naturaleza esconde acaban siendo presa de los intereses subjetivos propios o ajenos. Por tanto, aunque en la práctica puede darse una separación entre ciencias y ética, dicha separación no es saludable ni para las ciencias en sí, ni para un progreso adecuado del ser humano. El progreso científico contemporáneo muestra que la ciencia experimental, dentro de su propia autonomía, exige un complemento ético que no puede ser proporcionado por el mero progreso científico (Artigas 2009, 61).

Dicho complemento ético no consiste solo en una apertura genérica de la ciencia a la verdad, sino que tiene que ser aportado por los propios científicos, quienes no pueden eximirse de las responsabilidades de sus investigaciones.

Concluimos, por lo tanto, con Artigas que, en una civilización modelada cada vez más por el progreso científico, es esencial que los científicos (y los divulgadores) procuren ser rigurosos en sus formulaciones, tanto en el ámbito especializado como en el de la opinión pública (Artigas 2009, 168). El aporte de la ética personal a la actividad científica es fundamental y fundante, ya que esa disposición ética incluso es previa a la tarea científicaํ.

\footnotetext{
Algunos autores como Roger Penrose han defendido la importancia de la ética en relación a la ciencia: "it is more important than ever, in today's technological culture, that the scientific questions should not be divorced from their moral implications" (Penrose 2005, 22). Aunque quizá sin percibir todo su alcance: "though he [Penrose] neither separates moral from scientific activity, nor considers the moral as a limit to the scientific, but as something necessary, he does not reflect on the fruitful guidance ethics offers to scientific activity" (Herce 2016).
} 


\section{Prioridad de la ética sobre la actividad científica}

Jacques Monod se dio cuenta de esta prioridad de la ética al plantear su postulado de objetividad como condición del conocimiento verdadero. En sus propias palabras, tal postulado "constituye una elección ética y no un juicio de conocimiento ya que [...] no podría haber conocimiento 'verdadero' con anterioridad a esta elección arbitraria [...] es la elección ética de un valor primitivo la que funda el conocimiento" (Monod 1972, 176).

Artigas, por su parte, está dispuesto a identificar este postulado de objetividad con el "supuesto [ético] de que es posible, conveniente y eficaz adoptar la perspectiva científica para conseguir un conocimiento fiable acerca del mundo natural" (Artigas 2000, 343), pero sin reducirlo a una postura cientificista, sino más bien abriéndolo a otros ámbitos de conocimiento. Para Artigas la disposición ética no se limita al mero postulado de objetividad ni tampoco al mero conocimiento científico. Son los seres humanos los que deciden adoptar una perspectiva objetiva, creando los medios para que sea posible, trabajando dentro de esa perspectiva y obteniendo los resultados que la posibilitan. Pero también son esos mismos seres humanos:

quienes deberían integrar ese método y sus resultados dentro del marco más amplio de la experiencia humana. Si olvidamos ese marco más amplio, entonces la objetividad científica se convierte en una elección éticamente ciega que, tal como dice Monod, no nos conduciría a ninguna parte. Más exactamente, si usamos sus mismas palabras, esa elección nos conduciría a saber que estamos solos en la inmensidad indiferente de un universo del que hemos emergido solamente por azar. (Artigas 2000, 345)

Según Artigas, la búsqueda de la verdad y el compromiso con la objetividad son valores importantes. Valores éticos que son parte de la ciencia misma y que actúan como supuestos éticos de toda la empresa científica. Sin ellos la ciencia experimental carecería de sentido (Artigas 2000, 348). Dichos valores deberían encontrarse presentes en todo sujeto que hace ciencia, aunque de algún modo le trasciendan, ya que actúan como supuestos éticos de la empresa científica. 
La cuestión de los valores éticos implícitos en toda actividad científica es un tema que Artigas estudia con cierta profusión y sobre el que nos vamos a detener brevemente. Eso sí, no nos centraremos en desmenuzar todos los valores que considera Artigas, sino en distinguir entre los valores éticos institucionales de la ciencia y los valores éticos personales.

\section{Valores éticos institucionales y valores éticos personales}

Como se ha apuntado con anterioridad, Artigas resalta la interdependencia entre la ética de la actividad científica y la ética personal del científico, pero también subraya su distinción. Hasta el punto de que "los científicos pueden actuar de modo no ético, también en su trabajo científico. Sin embargo, el resultado de la ciencia experimental en su conjunto tiende, a la larga, a favorecer el respeto por la argumentación” (Artigas 2000, 356). Es decir, hay unos valores en la propia actividad científica que tienden a salir a flote, aunque el científico no los respete siempre y necesariamente.

Entre estos valores, Artigas señala: la búsqueda de la verdad, decir la verdad, la honestidad al informar de los resultados, la integridad, tratar honestamente la evidencia, la objetividad, el rigor, la cooperación, la modestia intelectual y la libertad de investigación. Valores científicos institucionales que se podrían corresponder con lo que Monod denomina ética de la objetividad y Artigas supuestos éticos de la actividad científica.

Obviamente, estos valores no son exclusivos de la ciencia experimental; sin embargo, forman parte de la vida institucional de la ciencia, y el progreso científico tiende a difundirlos [...] aunque, como sucede de ordinario con los recursos humanos, los medios que proporciona el progreso científico pueden ser utilizados bien o mal desde el punto de vista ético. (Artigas 2000, 400)

Luego, los valores científicos institucionales no parecerían, propiamente hablando, valores éticos, ya que los científicos pueden buscarlos mientras persiguen valores éticos personales de distinta índole. Sin embargo, desde un punto de vista objetivo, sí que poseen cierto carácter ético (Artigas 2000, 385-386). De ahí la distinción entre unos valores éticos institucionales 
y unos valores éticos personales, entre los que existe cierta independencia, pero no una radical separación. Veamos como Feyman y Bunge, respectivamente, señalan la relevancia de los valores éticos personales y de los valores éticos institucionales.

Richard Feynman, con su principio de integridad científica (o de honestidad a ultranza) formulado en la lección inaugural del curso 1974-75 en Caltech, muestra la importancia del carácter ético personal del científico a la hora de modelar la ciencia:

Puede ser, pues, interesante hablar explícitamente de una especie de integridad científica, un principio de pensamiento científico que equivale a una especie de honestidad absoluta, algo así como querer refutar lo hecho. Por ejemplo, si estamos realizando un experimento, deberíamos dar cuenta no solo de lo que nos parece que tiene de correcto, sino de todos los aspectos que a nuestro juicio podrían invalidarlo: otras causas que podrían explicar los resultados obtenidos; cosas que uno piensa han quedado descartadas por otros experimentos, y cómo funcionaron estos; todo lo que garantice que los demás puedan saber qué es lo que se ha descartado.

Si se conocen, deben darse los detalles que pudieran hacer dudar de la interpretación propia. Se debe hacer el máximo esfuerzo para explicar lo que no encaja, o pudiera no encajar [...]. En resumen, la idea consiste en esforzarse en dar la totalidad de la información para que los demás puedan juzgar con facilidad el valor de lo que se aporta, y no en dar solamente información que oriente el juicio en una u otra dirección. (Feynman 1974, 12)

Este proceso de no engañarse a sí mismo, de ser cuidadoso con los datos y las afirmaciones, de ser honesto y no engañar a los otros, de mostrar dónde se puede estar equivocado... es responsabilidad de los científicos, como individuos. Es propio de la ética personal del científico; aunque obviamente repercute sobre la ciencia.

Otro autor, Mario Bunge, ha resaltado una postura complementaria a la recién expuesta. Esta postura no se centra en que la actitud ética del científico sea esencial a la hora de hacer buena ciencia, sino en que la actitud científica (que de algún modo ya es una actitud ética, tal y como Bunge la 
presenta) puede ayudar a los científicos a mejorar éticamente. Es decir, que la ciencia promueve el desarrollo de unos valores éticos institucionales.

La adopción universal de una actitud científica puede hacernos más sabios: nos haría más cautos, sin duda, en la recepción de la información, en la admisión de creencias y en la formulación de previsiones; nos haría más exigentes en la contrastación de nuestras opiniones y más tolerantes con las de otros; nos haría más dispuestos a inquirir libremente acerca de nuevas posibilidades y a eliminar mitos consagrados que solo son mitos; robustecería nuestra confianza en la experiencia, guiada por la razón, y nuestra confianza en la razón contrastada por la experiencia; nos estimularía a planear y controlar mejor la acción, a seleccionar nuestros fines y a buscar normas de conducta coherentes con esos fines y con el conocimiento disponible, en vez de dominadas por el hábito y por la autoridad; daría más vida al amor a la verdad, a la disposición a reconocer el propio error, a buscar la perfección y comprender la imperfección inevitable; nos daría una visión del mundo eternamente joven, basada en teorías contrastadas, en vez de estarlo en la tradición, que rehuye tenazmente todo contraste con los hechos; y nos animaría a sostener una visión realista de la vida humana, una visión equilibrada, ni optimista ni pesimista. (Bunge 1976, 51)

Artigas está bastante de acuerdo con estas apreciaciones. La ciencia experimental conlleva todo un conjunto de valores éticos como poner en práctica la capacidad crítica, la disposición a rectificar cuando se detectan errores, la modestia intelectual, la cooperación, la objetividad; y es esencialmente una búsqueda de la verdad en la que el científico tiene que practicar una ética personal.

Sin embargo, sigue siendo verdad que la actividad científica nada nos puede decir acerca de los fines que hemos de buscar en nuestra vida. La ciencia experimental es incompetente para los temas que se refieren a los valores éticos personales (Artigas 2004,137). Esto se debe a que la ética no es consecuencia de la actividad científica, sino que la precede. Es necesario reconocer que lo ético, y lo metafísico añadiríamos, tienen un valor objetivo previo a la actividad científica. Al menos así lo reconoce Artigas. La actividad científica quedaría infravalorada si la desconectamos de sus dimensiones metafísica y ética, porque lo real, la verdad y lo bueno son previos a la actividad científica. 
Popper, que como veremos enseguida está abierto a las dimensiones ética y metafísica, percibe también esta necesidad. De hecho, señala tres principios como constitutivos de toda discusión racional que busca la verdad, no solo la verdad científica.

1. El principio de falibilidad: quizá yo estoy equivocado y quizá tú tienes razón. Pero es fácil que ambos estemos equivocados.

2. El principio de discusión racional: deseamos sopesar, de forma tan impersonal como sea posible, las razones en favor y en contra de una teoría definida y criticable.

3. El principio de aproximación a la verdad: en una discusión que evite los ataques personales, casi siempre podemos acercarnos a la verdad. Puede ayudarnos a lograr una mejor comprensión; incluso cuando no alcancemos un acuerdo (Popper 1992, 199).

Estos principios son tanto principios epistemológicos como éticos ya que implican la tolerancia, la igualdad y el respeto por el otro. Son requisitos previos de una disposición adecuada a discutir racionalmente las cosas. Son disposiciones éticas que sirven de supuesto ético para la actividad científica y que se encuentran entrelazadas con otros supuestos. Para Artigas estos otros supuestos son el ontológico y el epistemológico.

\section{Supuestos filosóficos de la ciencia}

Artigas considera tres supuestos filosóficos de la actividad científica. Sobre estos, el progreso científico ejerce una retroacción que permite justificarlos, corregirlos y ampliarlos.

El primero se refiere a la inteligibilidad o racionalidad de la naturaleza; puede ser denominado ontológico, y se encuentra estrechamente relacionado con el orden de la naturaleza. El segundo se refiere a la capacidad humana para conocer el orden de la naturaleza; puede ser denominado epistemológico, e incluye las diferentes modalidades de la argumentación científica. El tercero se refiere a los valores implicados por la actividad científica; puede ser denominado ético, e incluye la búsqueda de la verdad, el rigor, la objetividad, la modestia intelectual, el servicio a los demás, la cooperación, y otros valores relacionados 
con estos. Además, el progreso científico ejerce una retroacción sobre esos supuestos, ya que los retro-justifica, los enriquece, y los precisa. En verdad, dado que esos supuestos son condiciones necesarias para la existencia de la ciencia, el progreso científico es una condición suficiente para su existencia y nos permite determinar su alcance. (Artigas 2000, 19)

La ciencia experimental no tendría sentido ni podría existir si no se admitieran implícitamente estos supuestos ${ }^{2}$. Su estudio y el estudio de la retroacción del progreso científico sobre ellos es una tarea filosófica y proporciona un importante puente para conectar la ciencia experimental con la filosofía y con la teología (Artigas 2009, 174), así como con el comportamiento ético.

En el nivel ético, la actividad científica solo tendría sentido si se admite que la búsqueda de la verdad y el servicio a la humanidad son valores que merecen la pena ser perseguidos (Artigas 2004, 170). A la vez, la retroacción del progreso científico sobre sus supuestos éticos conlleva la necesidad de afrontar responsabilidades éticas que aumentan proporcionalmente con el progreso científico (Artigas 2000, 399).

En la obra de Artigas, la triada de supuestos recién presentada siempre aparece expuesta en el siguiente orden: supuestos ontológicos, epistemológicos y éticos. Cabría preguntarse si está hecho a propósito; si ese es el orden correcto; o si simplemente es una enumeración que corresponde a la estructura de algunos de los libros de Artigas.

Artigas no parece que lo aclare e inicialmente nos podríamos inclinar por la última opción. Sin embargo, cabe preguntarse si en la obra de Artigas existe algún tipo de orden distinto del expositivo cuando trata las cuestiones de los supuestos. Parecería que sí, que, si bien van siempre entrelazados, el supuesto ético no debería ocupar el último lugar. Para explorar esta posibilidad podríamos fijarnos en el análisis que Artigas hace de la obrar

Mancini $(2014,68-72)$ añade además un cuarto tipo de supuestos: los supuestos científicos. Estos últimos corrigen, amplían y justifican a la propia ciencia; a la vez que tienen una proyección sobre la filosofía. Artigas no los considera y nosotros tampoco lo haremos sino que tendremos solo en cuenta los tres supuestos apuntados por Artigas, en especial el ético, que es el objeto de nuestro artículo. 
de Popper a raíz de un par de intervenciones, entonces inéditas, del filósofo austriaco. Entramos así en la tercera parte de este artículo.

\section{La ética como clave hermenéutica de la obra de Popper}

Normalmente, las evaluaciones de la epistemología popperiana se centran en los elementos lógicos: la asimetría entre verificación y falsación o el problema de la inducción. Estos problemas son claves en su pensamiento. Sin embargo, hay que saber aproximarse a ellos teniendo en cuenta su relación con problemas más amplios y profundos, entre los que se incluye la responsabilidad ética personal (Artigas 2000, 236).

La importancia que Artigas da a la ética como clave hermenéutica de la obra de Popper se debe, en especial, al descubrimiento de un artículo del profesor Hubert Kiesewetter (1995). Este artículo llamó la atención de Artigas al considerar las raíces éticas de la epistemología de Popper. Posteriormente, una lectura más detallada le convenció de la importancia de la ética también para la filosofía de la ciencia popperiana (Artigas 1998b, 12).

Es posible interpretar el pensamiento de Popper adoptando como clave interpretativa las preocupaciones éticas, que son su auténtico motor [...]. Pero esa interpretación exige una relectura de la obra de Popper que no siempre es fácil, debido al énfasis que él pone en su falibilismo, y a la insuficiente base metafísica de su ética. Popper basa toda su filosofía en una "fe en la razón" que él mismo califica como "irracional". Se trata, en realidad, de una afirmación de la dignidad de la persona humana, de su libertad, de su responsabilidad, de la igualdad básica entre todos los hombres, de la paz y de la tolerancia. Si se acepta una metafísica abierta a la trascendencia, estos valores encuentran una justificación; en cambio, en el agnosticismo de Popper solo pueden ser justificados por sus consecuencias positivas. Dado que Popper estaba abierto a la metafísica, es posible conservar una parte importante de su pensamiento complementándola con una metafísica abierta a la trascendencia. Pero, en tal caso, ya no se trata de la posición de Popper tal como él la presenta, sino de una metafísica que incorpora una parte de la filosofía de Popper dejando fuera otra. (Artigas 2009, 84) 
Como consecuencia de este descubrimiento, Mariano Artigas publicó Lógica y ética en Karl Popper (1998b), un libro breve con comentarios a las dos intervenciones inéditas de Popper. En ese libro resalta cómo los dos documentos comentados influyen decisivamente en la interpretación que se debe hacer de la obra de Popper. En lugar de interpretar a Popper en clave del pancriticismo de Bartley, su discípulo, se debería acentuar que la inspiración principal del legado popperiano posee un carácter ético (Artigas 1998b, 11). Sin esta clave ética de lectura, según Mariano Artigas, se perdería la dimensión auténtica del Racionalismo Crítico propuesto por Popper.

Cuando Popper habla de crítica, racionalismo crítico o falibilismo, a menudo se está refiriendo a un marco más amplio, a un tema más complejo que incluye actitudes personales, ya que habla de honestidad intelectual, auto-crítica y modestia intelectual; de admitir nuestros errores, nuestra falibilidad, nuestra ignorancia... Lo cual implica una actitud ética (Popper 1992, 190).

Sin embargo, durante años, la discusión sobre el racionalismo crítico de Popper obvió este marco más amplio y se centró en el pancriticismo de Bartley. Dicha discusión desagradaba a Popper, quien además disintió públicamente de la interpretación que Bartley hacía de su filosofía. En 1992, en una intervención en Kyoto, Popper subrayó que esa discusión había perjudicado a su filosofía, porque se había centrado demasiado en un terreno abstracto, olvidando el aspecto ético (Artigas 1998b, 97).

Según Artigas, el racionalismo crítico de Popper no es una teoría o una doctrina, sino "una actitud que él [Popper] recomienda para que al menos se intente” (Artigas 1998b, 99). Se trata de valorar cómo debemos comportarnos con otras personas; un aspecto cuya importancia difícilmente puede sobrevalorarse (Artigas 1998b, 93). Como indica Artigas:

El racionalismo de Popper se refiere a una actitud, no es una teoría. Lleva a mantener las propias ideas abiertas a posibles rectificaciones, pero no es, en absoluto, una actitud iconoclasta. Precisamente es una actitud que, al basarse en unas razones morales, implica toda una serie de supuestos éticos. Con su decisión moral, Popper admite implícitamente toda una serie de supuestos que no está dispuesto a abandonar: supuestos que se refieren a la libertad, a la 
dignidad humana, a la justicia, a la igualdad, a la convivencia pacífica, al respeto, a la tolerancia. Lo que sucede es que le parecen tan obvios que ni siquiera se los plantea expresamente como supuestos. Quizá ésa sea una de las claves de los equívocos que puede provocar la filosofía de Popper: que se apoya en unos supuestos que Popper no examina expresamente. (Artigas 1998b, 103)

Algo parecido le pasa a Bartley. Tras resaltar el papel de la ética como clave hermenéutica de la obra de Popper, Artigas también destaca que la interpretación que Bartley hace del racionalismo crítico de Popper, en última instancia, es una actitud ética.

Popper ha subrayado que su racionalismo crítico es, ante todo, una actitud, y en concreto una actitud ética. Podría decirse que, al fin y al cabo, el pancriticismo de Bartley también subraya una actitud, la actitud crítica, y que también en este caso se trata de una actitud que tiene dimensiones éticas. De hecho, Bartley llegó al pancriticismo intentando resolver problemas existenciales relacionados con la religión y el compromiso último. Además, puede añadirse, en ambos casos se trata de una actitud ética frente a excesos irracionalistas: Popper desarrolla su racionalismo crítico frente al historicismo y al totalitarismo, y Bartley lo prolonga en su confrontación con el fideísmo irracionalista relacionado con el relativismo y el escepticismo. (Artigas 1998b, 94)

Llegados a este punto, ¿cabría afirmar que el supuesto ético es previo al supuesto epistemológico? Diría que, como supuesto que es y como se ha argumentado, el supuesto ético sí es previo a la actividad científica. Sin embargo, de esta conclusión no se deduce una prioridad del supuesto ético sobre el epistemológico. Esa interesante cuestión cabe formulársela, pero supera los límites del presente trabajo.

\section{Conclusiones}

Después de repasar los tres tipos de textos en los que Mariano Artigas habla de ética: (1) la ética como algo propiamente humano; (2) la relación de la ética con la actividad científica; y (3) la ética como clave hermenéutica de la obra de Popper; ha llegado el momento de hacer un balance y ver 
qué podemos decir sobre la importancia de la ética en la obra de Mariano Artigas. Una primera idea es que la ética es esencialmente humana. Esa dimensión ética del hombre se plasma en su actividad científica, ya que esta es humana; y además revierte sobre el ser humano, ya que la búsqueda de la verdad científica conlleva ciertos bienes éticos. Sin embargo, que el científico se deje transformar por la bondad de esos bienes éticos depende en última instancia de otros factores.

Con otras palabras, la búsqueda de la verdad científica es buena en sí pero no necesariamente para mí como científico porque puede tratarse de un bien que busco equivocadamente. De aquí la distinción y el entrelazamiento entre valores éticos institucionales de la empresa científica y valores éticos personales.

Por otro lado, en la obra de Artigas la ética aparece al final como corolario o colofón. Sin embargo, por la importancia que le da no puede ser un barniz. Es una dimensión esencial de la actividad científica, a la que precede.

Artigas lo dice explícitamente en varios lugares y resulta patente tanto cuando habla de la búsqueda de la verdad como una actitud o disposición ética fundamental, como en su análisis de la disposición ética como clave hermenéutica en la obra de Popper. Esa dimensión ética de la actividad científica se observa en que:

1. La ética no viene solo al final, para evaluar las consecuencias o implicaciones de una investigación. Aunque también aparezca ahí.

Por una parte, los resultados científicos proporcionan nuevos e importantes conocimientos acerca de la realidad, y las aplicaciones técnicas tienen con frecuencia implicaciones éticas que ponen en juego valores morales centrales. (Artigas 2004, 109)

2. La ética tampoco comparece solo a la hora de evaluar los medios que se utilizan para conseguir los objetivos científicos buscados. Aunque esté presente.

En la ciencia pura, la búsqueda de conocimiento solo está limitada, desde el punto de vista ético, por el tipo de medios que se utilicen para obtener ese conocimiento: no sería lícito, en ningún caso, utilizar medios moral- 
mente inaceptables con el pretexto de que permitirían obtener resultados interesantes o útiles. En cambio, la ciencia aplicada o tecnología contiene elementos éticos en todas sus dimensiones: en los fines que se buscan, en los medios que se utilizan, en la aplicación de los conocimientos a situaciones concretas [...] Además, resulta evidente que la ciencia experimental no proporciona, por sí misma, criterios éticos que permitan decidir la moralidad de sus aplicaciones. Cualquier avance científico puede ser utilizado para bien o para mal, desde el punto de vista ético. Y el enorme progreso científico de nuestra época lleva fácilmente a pensar que lo que es técnicamente posible es, automáticamente, éticamente aceptable. Quizá esto explique, en parte, que en nuestros días se sienta la necesidad de subrayar los límites de las ciencias desde las instancias éticas, humanistas y ecologistas. (Artigas 2009, 113-114)

3. La ética aparece también como una predisposición moral a buscar honestamente la verdad, a ser objetivos, a respetar la opinión de los demás... Sin esa predisposición personal todo lo demás parecerían parches éticos.

El doble objetivo de la ciencia tiene un carácter ético. En efecto, el objetivo teórico (conocimiento de la naturaleza) se relaciona con la búsqueda de la verdad y exige una actitud de objetividad, y el objetivo práctico (dominio controlado de la naturaleza) se relaciona con la consecución de medios que hacen posible una vida más humana, o sea, con el servicio a la humanidad.

Nos embarcamos en la empresa científica porque consideramos que sus objetivos son valores; en caso contrario, no los buscaríamos. (Artigas 2009, 275)

En la obra de Artigas se observa y se desarrolla aquello que ya señaló MacIntyre $(1978,30)$ : las ciencias encarnan una tarea moral. Esta tarea moral se concreta en que, por un lado, la ética comparece antes, durante y después de la actividad científica, porque es una dimensión esencial de esta. Mientras que, por otro lado, la actividad científica, en su conjunto, cataliza, potencia y promueve valores éticos, aunque ni los crea, ni los garantiza siempre. 


\section{Referencias}

Artigas, M. 1995. La inteligibilidad de la naturaleza. Pamplona: Eunsa.

-. 1998a. Filosofía de la naturaleza. Pamplona: Eunsa.

-. 1998b. Lógica y ética en Karl Popper. Pamplona: Eunsa.

-. 2000. La mente del universo. Pamplona: Eunsa.

-. 2004. Ciencia, razón y fe. Pamplona: Eunsa.

-. 2009. Filosofía de la ciencia. Pamplona: Eunsa.

Bunge, M. 1976. La investigación científica. Barcelona: Ariel.

Feynman, R. 1974. “Cargo Cult Science.” Engineering and Science, 37/7: 11-13.

Herce, R. 2016. "Penrose on What Scientists Know." Foundations of Science, 21/4:679-694. doi 10.1007/s10699-015-9432-0

Juan Pablo II. 1979. Carta encíclica Redemptor hominis. Disponible en http://w2.vatican.va/content/john-paul-ii/es/encyclicals/documents/hf_jp-ii_enc_04031979_redemptor-hominis.html

Kiesewetter, H. 1995. “Ethical Foundations of Popper's Philosophy.” In Karl Popper: Philosophy and Problems, edited by A. O’Hear, 275-288. Cambridge: Cambridge University Press.

MacIntyre, A. 1978. “Objectivity in Morality and Objectivity in Science.” In Morals, Science and Sociality, edited by H. T. Engelhardt, Jr. and D. Callahan, 21-39. Hastings-on-Hudson, New York: The Hastings Center.

Mancini, H. L. 2014. “Comentarios sobre la cosmovisión científica en Mariano Artigas." Scientia et Fides 2/1:59-79.

Monod, J. 1972. Chance and Necessity. New York: Vintage Books.

Penrose, R. 2005. The road to reality: A complete guide to the laws of the universe. New York: Knopf.

Popper, K. R. 1987. “Natural Selection and the Emergence of Mind”. In Evolutionary Epistemology, Rationality, and the Sociology of Knowledge, edited by G. Radnitzky and W. B. Bartley, III, 139-155. La Salle, Illinois: Open Court.

-. 1992. In Search for a Better World. Lectures and Essays from Thirty Years, London and New York: Routledge. 